\title{
Prediction of Mixed-mode Cracking Direction in Random, Short-fibre Composite Materials
}

\author{
L. W. Tsai and S. Y. Zhang* \\ Instıtute of Mechanics, Academıa Sınıca, Beijing (People's Republıc of Chına) \\ (Received 12 May 1987, revised version accepted 22 September 1987)
}

\begin{abstract}
$S U M M A R Y$
The prediction of crackıng direction in composite materıals is of significance to the design of composite structures. This paper presents several methods for predicting the cracking direction in the double grooved tension-shear specimen which gives mixed-mode cracking. Five different criteria are used in this analysis ' two of them have been used by other investigators and the others are proposed by the present authors. The strain energy density criterion proposed by G. C. Sih is modified to take account of the influence of the anisotropy of the strength on the direction of crack. The two fallure criteria of Tsal-Hill and Norris are extended to predict the crack orientation. The stress distributions in the near-notch zone are calculated by using the 8-node quadrilateral isoparametric fintte element method. The predictions of all the criteria except one are in good agreement with the experimental measurement. In addition, on the basis of the FEM results, the size of the zone in which the singular term is dominant is estımated.
\end{abstract}

\section{INTRODUCTION}

In strength analysis, in structural design or in designing against fracture in anisotropic materials, especially fibre-reinforced composite materials, prediction of crack initiation and growth direction are of great importance. In fracture analysis or the numerical simulation of fracture processes, the crack direction should be determined in advance. Many difficulties have been encountered for lack of a proper criterion of this kind. Thus, for

* To whom all correspondence should be addressed.

Composites Science and Technology 0266-3538/88/\$03-50 (C) 1988 Elsevier Applied Science Publishers Ltd, England Printed in Great Britain 
example, in finite element simulation, mesh-formation is only possible after the cracking direction is measured by laboratory test methods. However, no universal significance can be obtained from such limited tests. Attention has been pard to this aspect by some investigators (e.g. Ref. 1) recently, but further endeavour is required in order to obtain fully satisfactory results.

In Ref 1, three criteria for predicting the cracking direction were introduced and employed for unidirectional continuous fibre laminae with central cracks. These criteria are the normal stress ratio criterion, the tensor polynomial criterion, and the stress energy density criterion. In the present paper, the applicability of two of these criteria is studied for random, short-fibre composites under interlaminar shear fracture conditions in which mixed-mode cracking is involved. Owing to the incompetence of the strain energy density criterion, it has been modified to take account of the effect of strength anısotropy on the crackıng direction and a strain energy density ratio criterion is proposed. Furthermore, the Tsai-Hill criterion ${ }^{2}$ and Norris criterion ${ }^{3}$ which are widely used as fallure criteria are extended to predict the cracking direction. Comparison between predictions and experimental measurement has also been made. Details of the experimental and finite element (FEM) studies of interlaminar shear fracture of tensionshear specimens of CSM-GRP can be found in Refs 4-6.

In addition, with the FEM solution of the stress field and the characteristics of the normal stress ratio and the strain energy density ratio in the near-notch zone, the size of the zone in which the singular term is dominant is estimated.

\section{CRITERIA FOR PREDICTING CRACK INITIATION AND GROWTH DIRECTION}

Because of the lack of sufficient material properties data, the tensor polynomial criterion is hard to apply here, the remaining two criteria in Ref. 1 are therefore adopted for a mixed-mode cracking analysis of CSM-GRP.

\subsection{Normal stress ratio criterion}

This criterion, proposed by Gregory and Herakovich, ${ }^{1}$ assumes that the cracking direction is determined by the ratio of normal stress acting on a radial plane, $\sigma_{\theta \theta}$, to the related strength, $T_{\theta \theta}$. Cracking will take place in the direction in which the ratio at a given distance, $r_{0}$, from the tip, $R\left(r_{0}, \theta\right)$, is of maxımum value. Here, $R\left(r_{0}, \theta\right)$ is defined as (see Fig. 1)

$$
R\left(r_{0}, \theta\right)=\left.\frac{\sigma_{\theta \theta}}{T_{\theta \theta}}\right|_{r=r_{0}}
$$




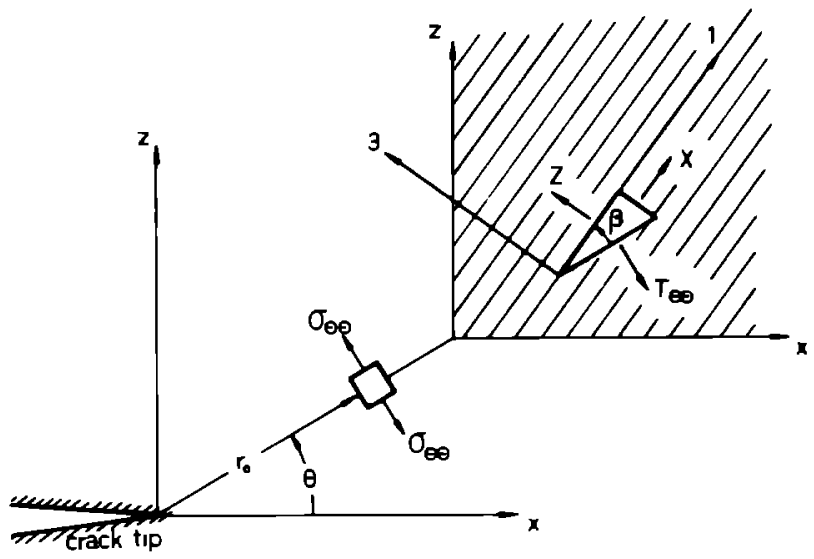

Fig. 1. Normal stress ratio parameters.

where $T_{\theta \theta}$ is the tensile strength, i.e. the critical value of the stress acting on the radial plane and defined as: ${ }^{1}$

$$
T_{\theta \theta}=X \sin ^{2} \beta+Z \cos ^{2} \beta
$$

and $\sigma_{\theta \theta}$ is the normal stress which can be calculated from:

$$
\sigma_{\theta \theta}=\frac{\sigma_{\mathrm{x}}+\sigma_{\mathrm{z}}}{2}+\frac{\sigma_{\mathrm{x}}-\sigma_{\mathrm{z}}}{2} \cos 2 \theta+\tau_{\mathrm{xz}} \sin 2 \theta
$$

where $\beta$ is the angle between the radial direction and the principal direction, 1 , of the material, $X$ and $Z$ are the tensile strength in the principal directions, 1 and 3 , of the material.

Equation (2) shows that $T_{\theta \theta}$ does not reflect the influence of shear strength on the cracking direction, in other words, this criterion assumes that the shear strength has no effect on cracking direction.

\subsection{Strain energy density criterion}

This criterion was first proposed by $\mathrm{Sih}_{1}{ }^{7}$ and is also sometimes called the Strain Energy Density Factor Criterion. It supposes that crack initration occurs in the radial direction, along which the local strain energy density possesses a minimum value, r.e.

$$
\frac{\partial S}{\partial \theta}=0 \quad \text { and } \quad \frac{\partial^{2} S}{\partial \theta^{2}}>0 \quad \text { at } \theta=\theta_{\mathrm{c}}
$$

where

$$
S=\frac{r}{2}\left(\sigma_{\mathrm{x}} \varepsilon_{\mathrm{x}}+\sigma_{\mathrm{z}} \varepsilon_{\mathrm{z}}+\tau_{\mathrm{xz}} \gamma_{\mathrm{xz}}\right)
$$


is so-called strain energy density factor. This criterion has been widely used in isotropic materials since it was first proposed, and it has also frequently been used for composite materials (e.g. Ref. 8). But for composites, the results are commonly found to have significant deviations from experımental data (e.g. Ref. 1): this can also be seen in the present paper.

According to eqn (5), strength properties of the material are not involved, and the influence of strength anisotropy on cracking direction is not reflected in this criterion. However, for anısotropic composite materials, the anısotropy of strength is much stronger than that of elastic properties. For a unidırectional lamına, for example, the longitudinal modulus may be larger than the transverse modulus by a factor of 10 , whereas the strengths in the two directions may differ by as much as two orders of magnitude. This is probably the reason for the failure of the strain energy density criterion. As a modification of the criterion, a strain energy density ratio criterion is proposed by the present authors.

\subsection{Strain energy density ratio criterion}

Firstly, the stress and strain ratios are introduced. Stress ratios are defined as ratios of the stress components in the material principal direction to the related failure strengths, i.e.

$$
\bar{\sigma}_{1}=\frac{\sigma_{1}}{X}, \quad \bar{\sigma}_{3}=\frac{\sigma_{3}}{Z}, \quad \bar{\tau}_{13}=\frac{\tau_{13}}{S}
$$

where $X$ and $Z$ are the tensile strengths in the material principal (1- and 3-) directions, $S$ is the shear strength, and $\sigma_{1}, \sigma_{3}$ and $\tau_{13}$ are stress components in the material coordinate system. Similarly, the strain ratios are the ratios of strain components in the material principal directıons to their related critical strains, i.e.

$$
\bar{\varepsilon}_{1}=\frac{\varepsilon_{1}}{\varepsilon_{1 \mathrm{c}}}
$$

If the material behaves elastically,

$$
\varepsilon_{1 \mathrm{c}}=\frac{X}{E_{11}}
$$

then, we have

$$
\bar{\varepsilon}_{1}=\frac{\varepsilon_{1}}{X / E_{11}}=\frac{E_{11} \varepsilon_{1}}{X}
$$

Similarly,

$$
\bar{\varepsilon}_{3}=\frac{E_{33} \varepsilon_{3}}{Z} \quad \bar{\gamma}_{13}=\frac{G_{13} \gamma_{13}}{S}
$$


where $E_{11}, E_{33}$ and $G_{13}$ are the moduli in the material principal directions and $\varepsilon_{1}, \varepsilon_{3}$ and $\gamma_{13}$ are related strain components. Thus, the strain energy density ratio can be defined as

$$
\bar{S}=\frac{1}{2}\left(\bar{\sigma}_{1} \bar{\varepsilon}_{1}+\bar{\sigma}_{3} \bar{\varepsilon}_{3}+\bar{\tau}_{13} \bar{\gamma}_{13}\right)
$$

Obviously, the stress and strain ratios are dimensionless parameters, and the strain energy density ratio is also dimensionless. Substituting the stress-strain relation into eqn (10) gives a stress formulation of $\bar{S}$

$$
\bar{S}=\frac{1}{2}\left[\left(\frac{\sigma_{1}}{X}\right)^{2}+\left(\frac{\sigma_{3}}{Z}\right)^{2}-\frac{v_{13}}{E_{11}} \sigma_{1} \sigma_{3}\left(\frac{E_{11}}{X^{2}}+\frac{E_{33}}{Z^{2}}\right)+\left(\frac{\tau_{13}}{S}\right)^{2}\right]
$$

The strain energy density ratio criterion can be stated as follows. For anisotropic materials, crack intiation and propagation are assumed to occur in the radial direction along which the local strain energy density ratio possesses a minimum value. Clearly, this criterion will reduce to Sih's strain energy density criterion when the material is isotropic.

Motivated by eqn (11), which is very similar to the expressions of the Tsai-Hill criterion ${ }^{2}$ and the Norris distortional energy criterion ${ }^{3}$ which are normally used as failure criteria, one can extend these two criteria for predicting the crack initiation and growth direction.

\subsection{Extended Tsai-Hill criterion}

The Tsa1-H1ll criterion ${ }^{2}$ is based on the distortional energy of materials. It assumes that failure occurs when the distortional energy, $S_{\mathrm{TH}}$, reaches unity, where

$$
S_{\mathrm{TH}}=\left(\frac{\sigma_{1}}{X}\right)^{2}+\left(\frac{\sigma_{3}}{Z}\right)^{2}-\frac{\sigma_{1} \sigma_{3}}{X^{2}}+\left(\frac{\tau_{13}}{S}\right)^{2}
$$

From the similarity between eqn (11) and eqn (12), when used for predicting the cracking direction one supposes that the distortional energy, $S_{\mathrm{TH}}$, will reach a minimum value in the cracking direction.

\subsection{Extended Norris criterion}

In the same way as section 2.4 , one supposes that the local Norris' distortional energy, ${ }^{3} S_{\mathrm{N}}$, given by:

$$
S_{\mathrm{N}}=\left[\left(\frac{\sigma_{1}}{X}\right)^{2}+\left(\frac{\sigma_{3}}{Z}\right)^{2}-\frac{\sigma_{1} \sigma_{3}}{X Z}+\left(\frac{\tau_{13}}{S}\right)^{2}\right]^{1 / 2}
$$

will possess a minimum value in the cracking direction.

One now uses the above five criteria to predict the mixed-mode crackıng direction of the specimen shown in Fig. 2 under tensile loading. 


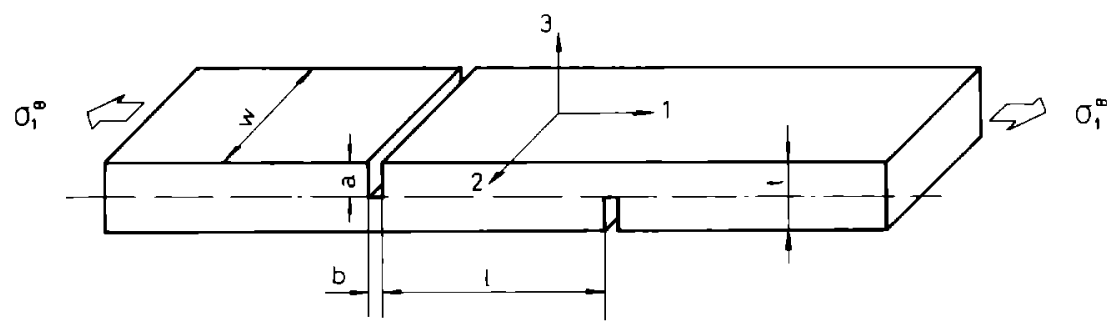

Fig. 2. A double-grooved tensıon-shear specımen

\section{CALCULATION AND DISCUSSION}

The specimen shown in Fig. 2 is a double-grooved tension-shear specimen for measuring the interlaminar shear strength as specified by Britush Standard BS4993 (1973). Details of the experıments can be found in Ref. 4. The material used is a laminated plate made of 9 layers of chopped strand mat (CSM) of glass fibre impregnated with polyester resın, the glass fibre content, $V_{f}$, being about 0-30. From video recordings of the experiment, cracks are seen to initiate and propagate along a direction of about $18^{\circ}$ to the tensile axis from the corners of the roots of the notches (see Fig. 3).

There is still no analytical solution avallable for the plane-strain problem shown in Fig. 2. Thus an 8-node quadrilateral, isoparametric, finite-element analysis is used here. The material is considered to be orthotropic, with its principal direction being defined in the global coordinates (see Fig. 2). The FEM mesh pattern is given in Fig. 4 and an enlarged view of the near-notch area is shown in Fig. 5.

The dimensions of the specimen are as follows (see Fig. 2): $l=25.0 \mathrm{~mm}$; $t=8.0 \mathrm{~mm} ; a=4.0 \mathrm{~mm}$; and $b=1.5 \mathrm{~mm}$. Only a part of the specimen, with a total length of $44.0 \mathrm{~mm}$, has been calculated. The material properties

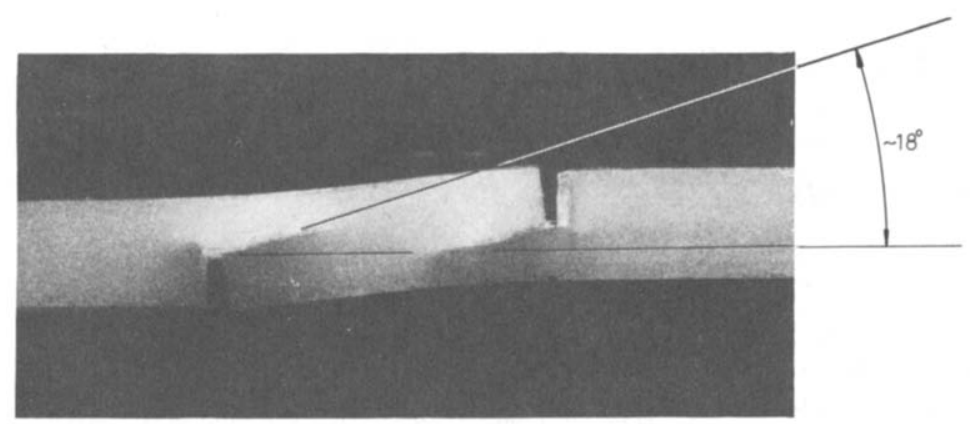

Fig. 3. A photograph of the specimen showing cracks at the corner of a notch 


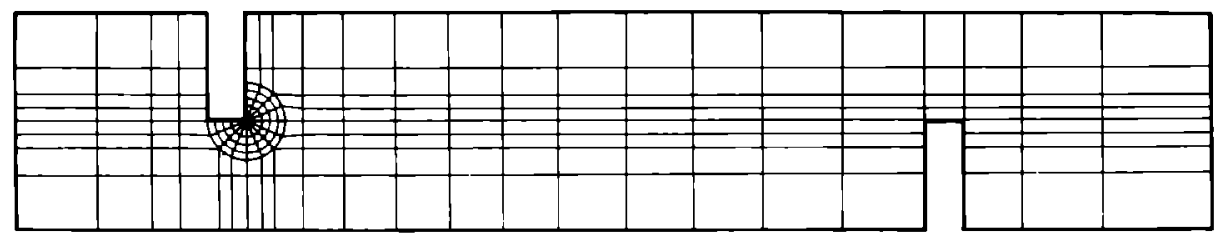

Fig. 4. Finite element mesh pattern

are: ${ }^{4} \quad E_{11}=9 \cdot 81 \mathrm{GPa}, E_{33}=5 \cdot 20 \mathrm{GPa}, v_{13}=0 \cdot 34, G_{13}=1.43 \mathrm{GPa}, X=$ $120.0 \mathrm{MPa}, Z=9.0 \mathrm{MPa}, S=29 \cdot 0 \mathrm{MPa}$.

Boundary conditions are that the left-hand end of the specimen is fixed and the transverse displacement of the mid-point at the right-hand end is constrained. A uniform traction is applied to the right-hand end.

Before cracking, the material behaves basically in a linear elastic manner. Thus the analysis is restricted to the range of linear elasticity. The deformed mesh pattern obtained by FEM is shown in Fig. 6 .

\subsection{Analysis of the notch-tip fields}

The calculations, with the preceding criteria, are all performed on a circle which has its center at the tip (or corner) of the notch. The radius of the circle

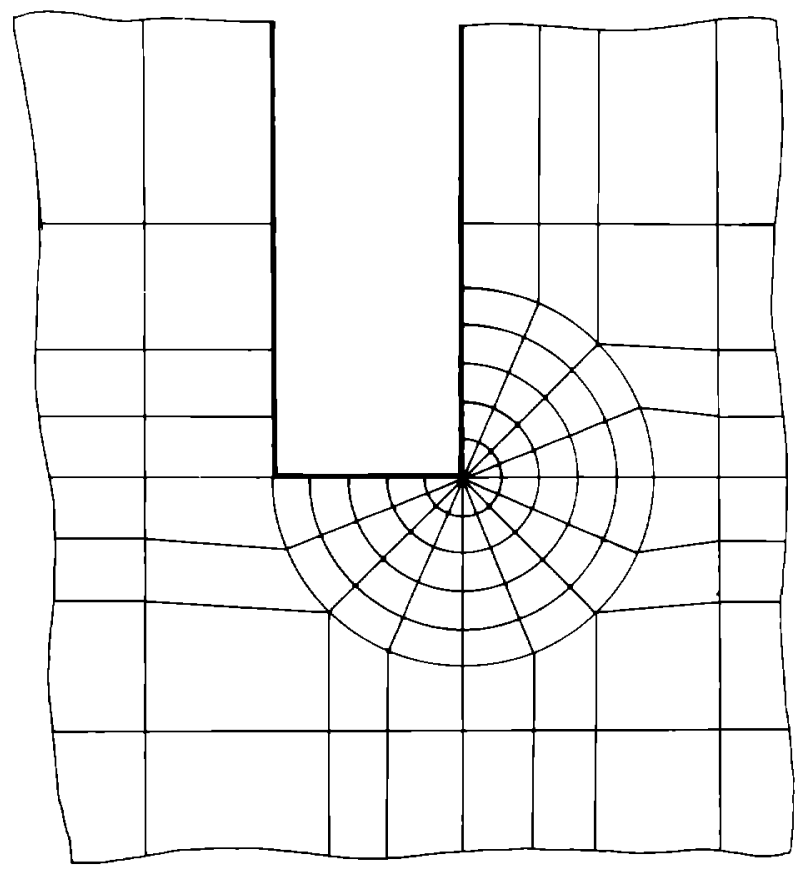

Fig. 5. Enlarged view of the mesh pattern near the notch root 


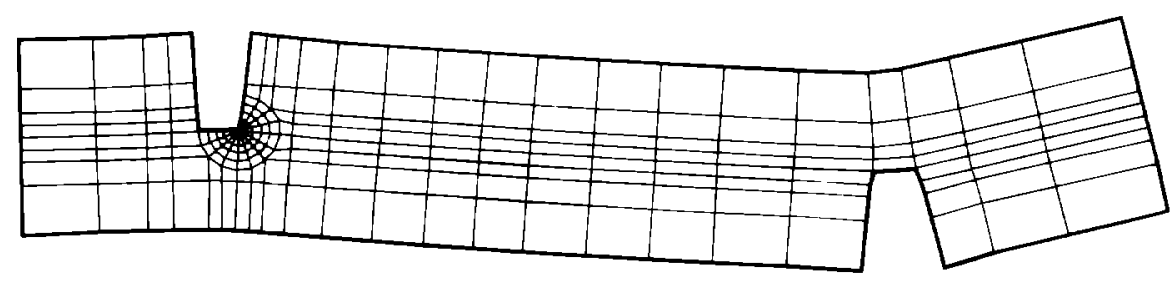

Fig. 6. Deformed finıte element mesh pattern

should be chosen so that the circle is withın the zone in which the crack-tıp singular terms dominate. Within the singular fields, the radius, $r_{0}$, can be chosen arbitrarily. But here, the FEM technique gives a global solution, and it is therefore necessary to have an evaluation of the size of the singularitydominated zone before predictıng the crackıng direction.

Figures 7-9 show the variations of the stresses near the corner as functions of $\theta$ at different radii, $r_{0}$, where $\theta$ is defined as in the legend of Fig. 7. Figures 10 and 11 show the normal stress ratio and the strain energy density ratio as functions of $\theta$ respectively

In Figures 7-9, the stress curves are basically similar to each other on different rad 11 within the range of $0^{\circ}-180^{\circ}$, but when $\theta>180^{\circ}$, the stress field is severely affected by the other tip and the ligament and the shapes of the curves also change notably. The shapes of the curves remain unchanged in

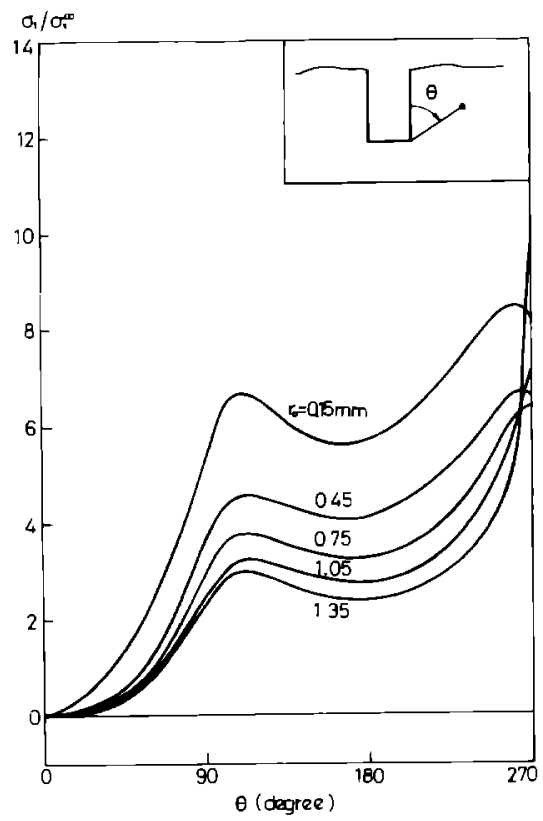

Fig. 7. Variation of $\sigma_{1} / \sigma_{1}^{\star x}$ with $\theta$ for different radı 


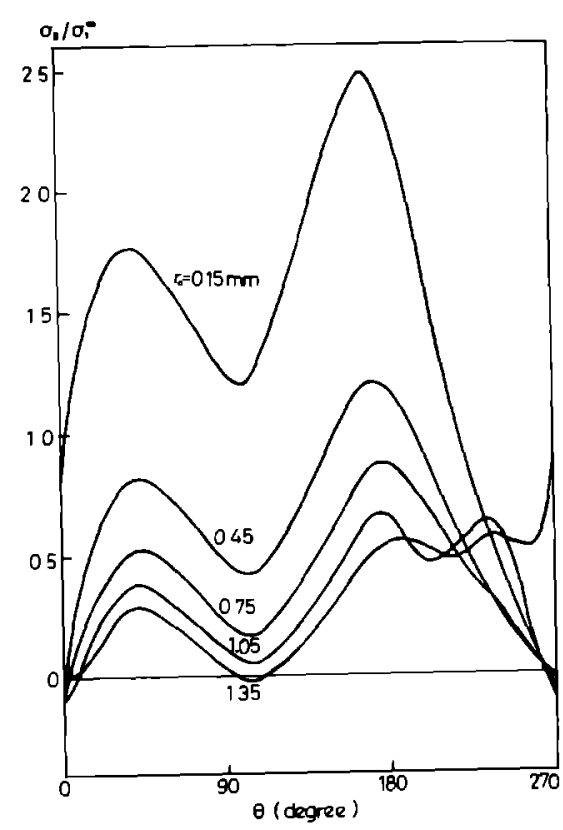

Fig. 8. Variation of $\sigma_{3} / \sigma_{1}^{\pi}$ with $\theta$ for different radil.

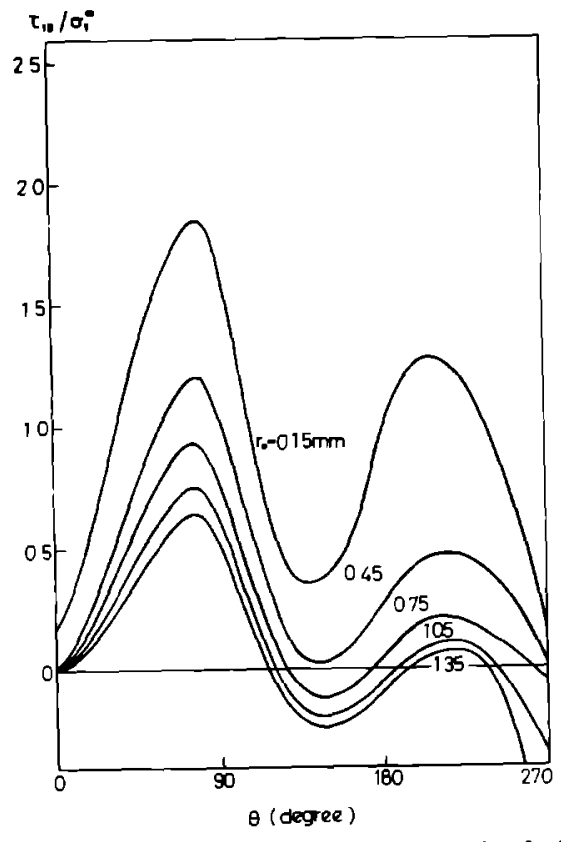

Fig. 9. Variation of $\tau_{13} / \sigma_{1}^{\infty}$ with 0 for different radıl

the range of $r_{0} \leq 0.45 \mathrm{~mm}$, but changes occur when $r_{0} \geq 0.75 \mathrm{~mm}$, and the changes become more severe with the increase of the radius.

In Fig. 10, when $r_{0} \geq 0.75 \mathrm{~mm}$, the second peak generally arises with the radius increased, the curves changing very regularly.

As for the strain energy density ratio in Fig. 11, the positions of minimum values are almost located at the same angles when the radius, $r_{0} \leq 0.45 \mathrm{~mm}$. Outside this range of radii, the positions of the minimum values deviate significantly and the shapes of the curves change pronouncedly.

Thus, we are able to estımate that the dominant zone of the singular field is within a circle of radius $0.45 \mathrm{~mm}$, 1.e., the size of the singularity-dominated zone is about one third of the width of the notch.

\subsection{Prediction of the cracking direction}

Having thus estimated the size of the singularity-dominated zone, we can now choose a proper radius and calculate the values of the normal stress ratio, the strain energy density, the strain energy density ratio, and the Tsai-Hill and Norris distortional energies as functions of $\theta$. The radius of the circle chosen is $r_{0}=0.15 \mathrm{~mm}$, along which the above five functions are computed. The results are shown in Figs 12 to 16. The directions predicted 


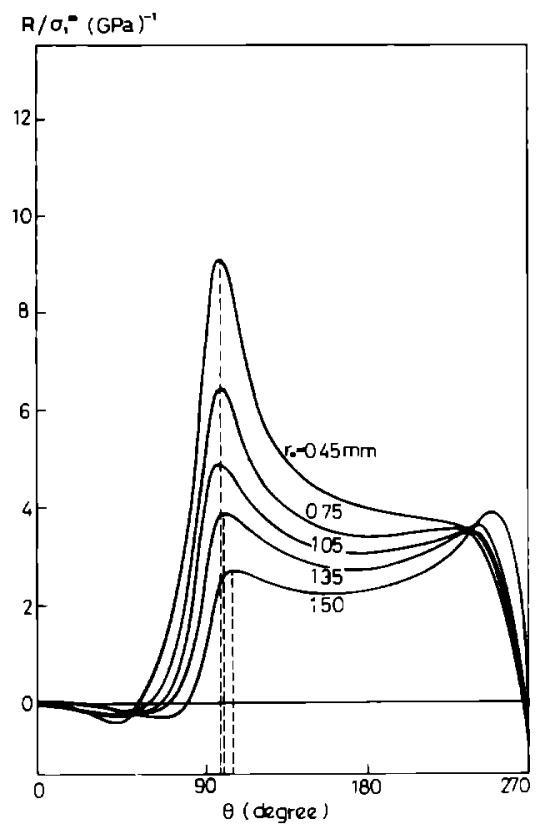

Fig. 10. Variation of normal stress ratio with $\theta$ for different radı

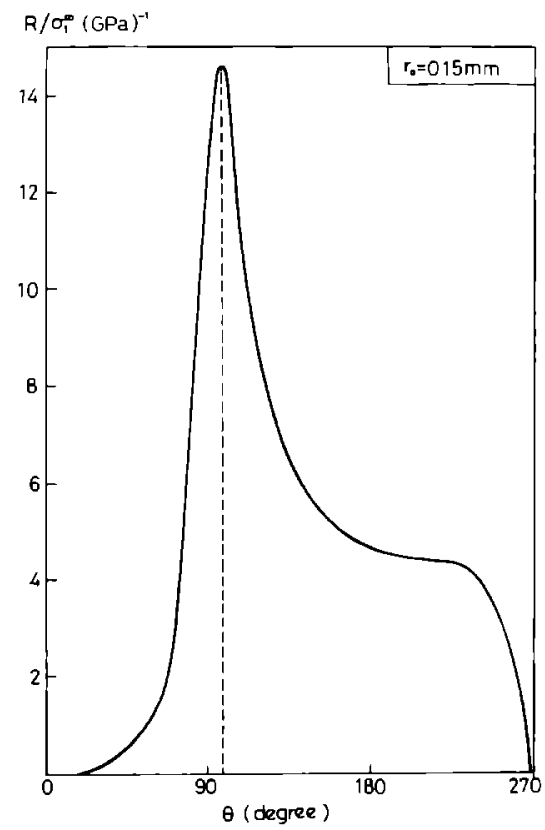

Fig. 12. Prediction of cracking direction by the Normal Stress Ratio Cnterion.

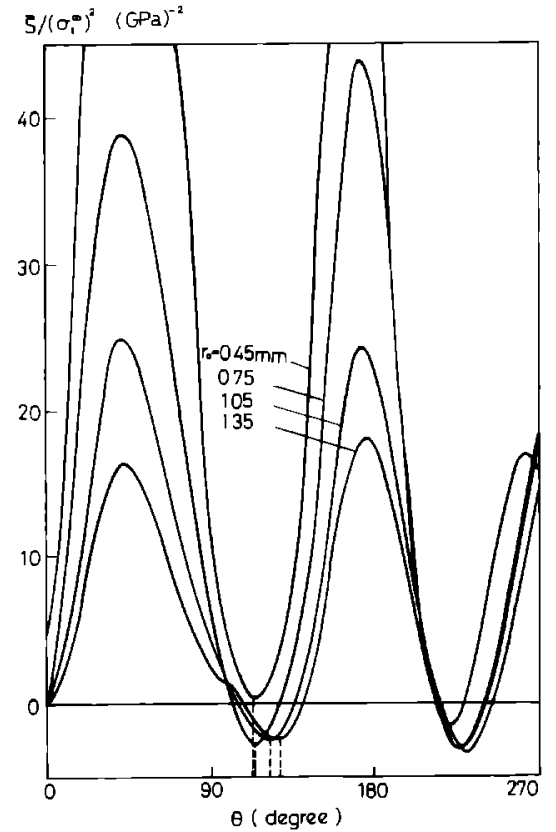

Fig. 11. Varıatıon of straın energy density ratio with $\theta$ for different radı

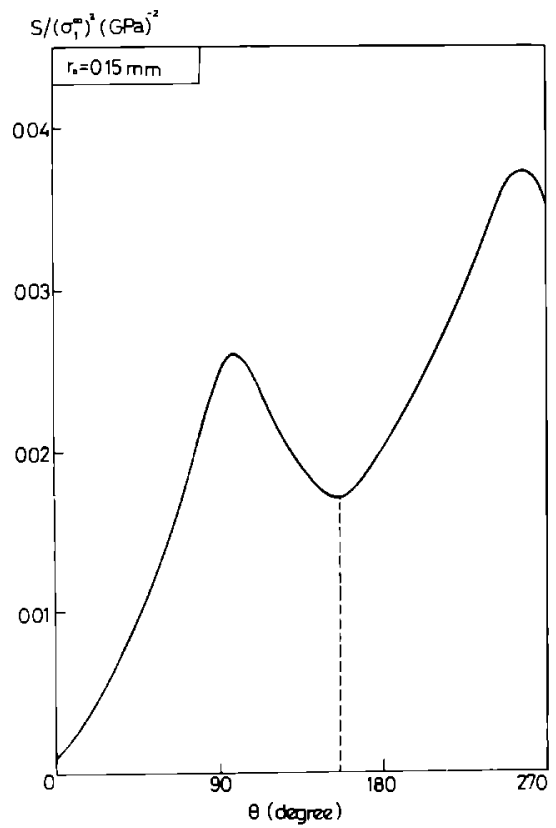

Fig. 13. Prediction of the cracking direction by the Strain Energy Density Criterion. 
TABLE 1

Predicted Crackıng Directıons and their Deviatıons (Experımental value $108^{\circ}$ )

\begin{tabular}{lcc}
\hline \multicolumn{1}{c}{ Criterion } & $\begin{array}{c}\text { Predicted angle } \\
\text { (degree) }\end{array}$ & $\begin{array}{c}\text { Deviation from } \\
\text { experiment (degree) }\end{array}$ \\
\hline Normal stress ratio & 98 & -10 \\
Strain energy density & 155 & 47 \\
Strain energy density ratio & 109 & 1 \\
Extended Tsal-Hill & 105 & -3 \\
Extended Norris & 108 & 0
\end{tabular}

by the criteria mentioned above are listed in Table 1 , in which deviations of all the predicted values from experimental measurements are also given.

From Table 1, we note that all of the criteria, except the strain energy density criterion, predict good results. The deviation of the normal stress ratio criterion is slightly larger than the predictions of the last three criteria, probably because of the exclusion of the shear strength from the strength expression, but the results are approximately correct. The deviations of the last three criteria fall within the scatter of the experimental data. In the

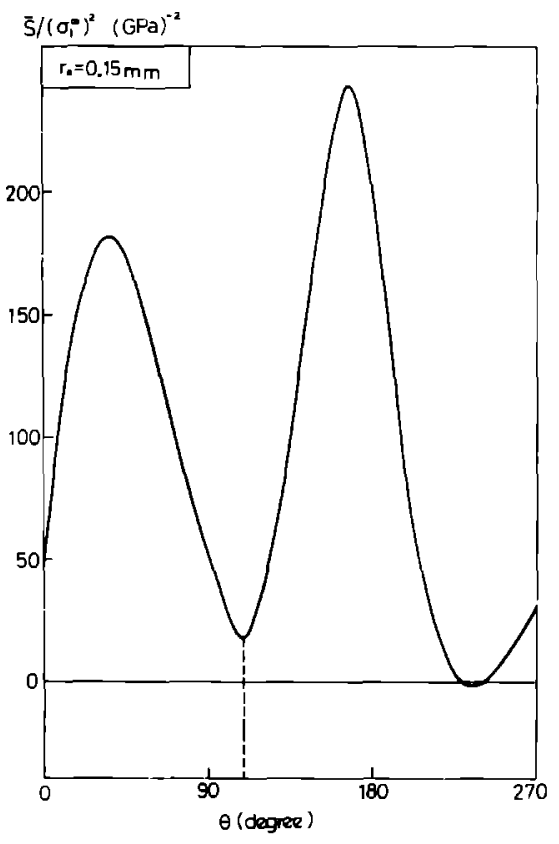

Fig. 14. Predıction of the crackıng direction by the Strain Energy Density Ratio Critenon.

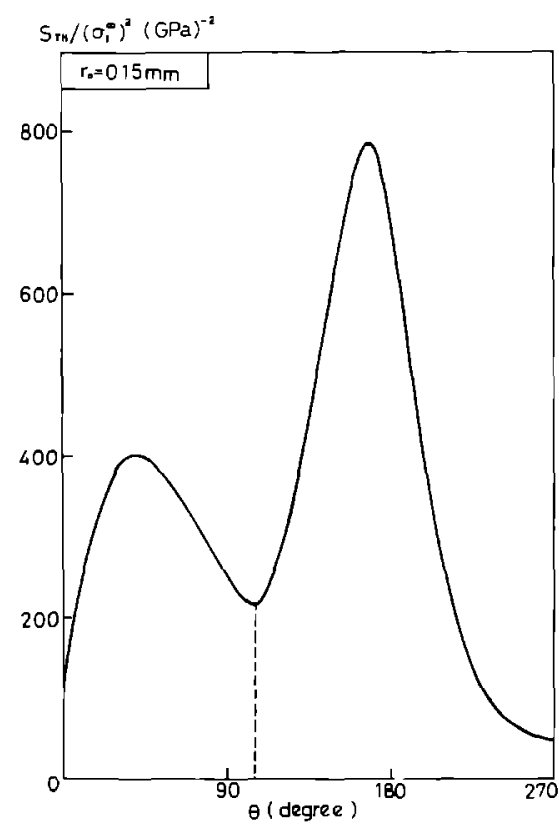

Fig. 15. Prediction of the cracking directıon by the Extended Tsai-Hill Criterıon. 


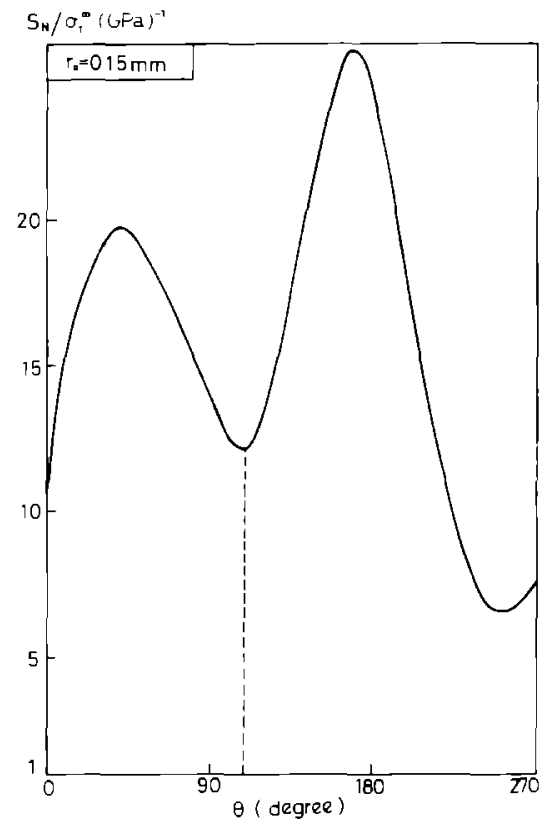

Fig. 16. Prediction of the cracking direction by the Extended Norris Criterion.

experiments, it has been found that not all the cracking directions are the same. Cracking does not lead to the formation of a straight, smooth crack, and the cracks deviate slightly from their origınal directıons at later stages of crackıng. All of these reasons may account for the deviations of the predicted cracking directions from the measured values. Generally speakıng, the results predicted by the last three criteria are satisfactory.

The difference predicted by the extended Tsai-Hill and Norris criteria is $3^{\circ}$. This suggests that strength parameters play an important role in predicting the cracking direction since the only difference in their expressions is that different strength parameters are involved in the coupled terms, namely, the former is $X^{2}$ (see eqn (12)) and the latter $X Z$ (see eqn (13)). But whether the Poisson ratio is considered or not has less effect on the prediction (see eqns (11) and (13)).

In addition, it has been observed that all of the energy-type criteria (apart from the normal stress ratio criterion, four others are of the energy-type) predict the crackıng direction by minımum values of the functions, which is coincident with Sih's criterıon for isotropic materials. This can be explained by reference to the system potential energy, as demonstrated in Ref 7 If a cracked body is subjected to tractions only, then the potential energy is equal to the negative of the strain energy. A minımum value of strain energy corresponds to a maximum value of potential energy, which implies an unstable equilibrıum state. So the strain energy density criterion predicts 
cracking along the direction of minimum strain energy density. The other energy-type criteria have interpretations similar to that for the strain energy density criterion. In some cases, there occur more than one minimum valuein this case, the cracking direction clearly associates with the maximum one of these values. On account of the fact that for all points at an unstable state, the strain energy (or the energies with other forms) must associate with the stress and strain levels, cracking tends to occur at higher levels of stress and strain

From the point of view of applications, the normal stress ratio criterion, although with some inaccuracy, may have a broader application especially in FEM simulations of fracture processes, for it predicts the cracking direction with maxımum value. This is a very convenient characteristic of the criterion.

\section{CONCLUSIONS}

In summary, we may draw the following conclusions:

1. Predictions of the strain energy density ratio criterion, extended Tsal-Hill criterion and extended Norris criterıon may give satisfactory results. The normal stress ratio criterion can also give a reasonably good result, although with some inaccuracy. However, owing to ignorance of the effect of the strong anısotropy of the material strength, the strain energy density criterion cannot be applied.

2. The FEM technique estimates the size of the singularity-dominated zone which has a radius less than $b / 3$.

3. Four energy-type criteria predict the crackıng direction by minimum values. When more than one minımum value appears, the cracking direction associates with the largest of these values.

\section{REFERENCES}

1. M. A Gregory and C. T Herakovich, Predictıng crack growth direction in unıdırectıonal composites, J. Comp. Mater., 20 (1) (1986), pp. 67-85.

2. R. M. Jones, Mechanics of Composite Materials, McGraw-Hill, New York, 1975.

3 M. J Owen, Biaxial failure of GRP--mechanisms, modes and theories, Composite Structure 2. Proc 2nd Inter Conf. on Comp Struct., Applied Science Publishers, London, 1983, pp 21-39

4. S Y. Zhang, P D. Soden and P. M. Soden, Interlamınar shear fracture of chopped strand mat glass fibre-reinforced polyester laminates, Composites, 17 (2), (1986), pp 100-10

5. S Zhang and C M Leech, FEM analysis on mixed-mode fracture of CSM-GRP, Engng Frac. Mech, 23 (3), (1986), pp 521-35 
6 S. Zhang, A mixed-mode crack analysis on interlamınar shear fracture of CSMGRP by FEM, Proc Inter. Symp on Comp. Mater. \& Struct, Be1jıng, Technomic (1986), pp. 598-603.

7 G. C Sih, A special theory of crack propagation. In G C Sih (ed), Mechanics of Fracture, Vol. I Methods of Analysis and Solutions to Crack Problems, Noordhoff, The Netherlands, (1973), pp XXI-XLV

8. G C Sı, E. P. Chen, S. L. Huang and E J. McQuillen, Material characterization on the fracture of filament-reinforced composites, J. Comp Mater., 9 (2), (1975), pp $167-86$ 